\title{
EFFECTS OF RADIATION ON AEROSOL BEHAVIOR
}

Task 56

\section{Topical Report}

Larry D. Reed

James A. Gieseke

Hans Jordan

Thas seport was prepared as an account of work Thensed the Unted States Government Nelthe the United States nor the United States Eneng Research and Development Adnum their contractors Des, makes any expes or inphed, or as wansaly, express or the accuracy, completene s of any information, apparatus, product or infange priately owned rights

BATTELLE

Columbus Laboratories

Columbus, Ohio

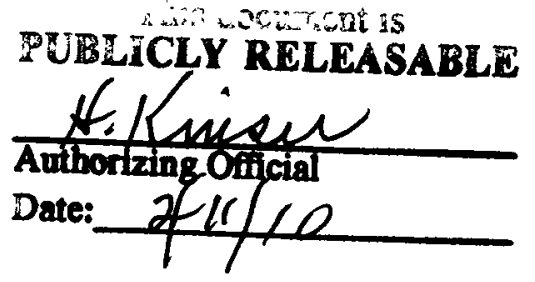

Report Date: December 18, 1975 
$\bullet$

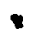

$\downarrow$ 


\section{DISCLAIMER}

This report was prepared as an account of work sponsored by an agency of the United States Government. Neither the United States Government nor any agency Thereof, nor any of their employees, makes any warranty, express or implied, or assumes any legal liability or responsibility for the accuracy, completeness, or usefulness of any information, apparatus, product, or process disclosed, or represents that its use would not infringe privately owned rights. Reference herein to any specific commercial product, process, or service by trade name, trademark, manufacturer, or otherwise does not necessarily constitute or imply its endorsement, recommendation, or favoring by the United States Government or any agency thereof. The views and opinions of authors expressed herein do not necessarily state or reflect those of the United States Government or any agency thereof. 


\section{DISCLAIMER}

Portions of this document may be illegible in electronic image products. Images are produced from the best available original document. 
EFFECTS OF RADIATION

ON AEROSOL BEHAVIOR

Larry D. Reed, James A. Gieseke and Hans Jordan

\section{INTRODUCTION}

The influence of radioactivity on the behavior of aerosol particles is a subject of potential importance to scientists attempting to predict aerosol concentration levels in containments following postulated nuclear reactor accidents. It is also a subject which, except for a few brief notes, has received little attention. The purpose of this report, then, is twofold: (i) to postulate, in a general manner, possible physical mechanisms resulting from a particle's radioactivity which may influence its transport, deposition, agglomeration and possible resuspension in accident situations, and (ii) to present order of magnitude calculations which demonstrate the importance of each mechanism in aerosol behavior predictions.

The influencing mechanisms have been divided into three categories: Interna1 Heat Generation, Momentum Exchange Effects, and Electrical Charging Effects. Due to energy dissipation within the aerosol prior to the actual emission of a "swift particle", the aerosol may become heated. This concelvably could affect sedimentation velocities as well as agglomeration rates. Similarly, the momentum increment experienced by the aerosol at the moment of "swift particle" emission could potentially serve to eject it from surfaces and agglomerates and may also add random motion to the aerosol suspended in a gaseous medium. Finally, electrical charging of an aerosol can influence its behavior. The critical question to be answered here concerns the extent to which the aerosols may become charged due to their radioactivity and the length of time that they may retain this charge. If indeed they do become and remain charged, this effect could lead to particle ejections from surfaces, break-up of agglomerates, and modification of agglomeration and diffusional deposition rates. 


\section{CHARACTERISTIC DECAY TIMES}

Each of the mechanisms mentioned above depends strongly on the number of radioactive emissions that an aerosol particle of given size is expected to experience per unit time. For the case of alpha decay, the number of disintegrations per unit time, $\dot{\mathrm{N}}_{\alpha}$, for a spherical particle of radius $r$ is simply

$$
\dot{\mathrm{N}}_{\alpha}=\frac{4}{3} \pi \mathrm{r}^{3} \rho \mathrm{Y}_{\alpha}
$$

where $\rho$ is the material density and $Y_{\alpha}$ the alpha yleld of the radioactive species of interest. In Table 1 , values of $\dot{\mathrm{N}}_{\alpha}$ are presented for several sizes of various plutonium isotope aerosols. Larger aerosol particles, with their greater mass, experience more alpha emissions per second than the smaller particles. Clearly if a reasonable alpha emission rate is not experienced by the aerosol particles, then the radiation effects discussed above are negliglble. Thus, examination of Table 1 reveals that although the plutonium isotopes 242 and 244 could probably be discarded from further study at this stage, the other isotopes, particularly in the case of large particles, are certainly candidates for radioactive effects.

\section{INTERNAL HEAT GENERATION}

Condider now the heat generation within an aerosol particle due to its radioactive decay. In the extreme case, it can be assumed that a11 the alpha energy of every disintegration that occurs within the aerosol is dissipated inside the aerosol before the alpha particle reaches the gas-particle interface. The energy dissipation rate is simply the alpha energy associated with each disintegration times the number of disintegrations occurring per unit time:

$$
\dot{\mathrm{Q}}=\frac{4}{3} \pi r^{3} \rho \mathrm{Y}_{\alpha} \mathrm{E}_{0}
$$


TABLE 1. NUMBER OF ALPHA DISINTEGRATIONS PER SECOND FOR VARIOUS PARTICLE SIZES OF PLUTONIUM AEROSOL

\begin{tabular}{|c|c|c|c|c|c|c|c|c|}
\hline $\begin{array}{c}\text { Particle } \\
\text { Radius, } \\
\mu \mathrm{m}\end{array}$ & $\begin{array}{l}\text { Particle } \\
\text { Volume, } \\
\mathrm{cm}^{3}\end{array}$ & $\begin{array}{c}\mathrm{Pu} \\
\mathrm{Pu}^{236} \\
19.4 \\
1.97 \times 10^{13}\end{array}$ & $\begin{array}{c}\mathrm{PuO}_{2} \\
\mathrm{Pu}_{238} \\
11.1 \\
6.47 \times 10^{11}\end{array}$ & $\begin{array}{c}\mathrm{PuO}_{2} \\
\mathrm{Pu}_{239} \\
11.1 \\
2.27 \times 10^{9}\end{array}$ & $\begin{array}{c}\mathrm{PuO}_{2} \\
\mathrm{Pu}_{240} \\
11.1 \\
8.38 \times 10^{9}\end{array}$ & $\begin{array}{c}\mathrm{PuO}_{2} \\
\mathrm{Pu}_{242} \\
11.1 \\
1.44 \times 10^{8}\end{array}$ & $\begin{array}{c}\mathrm{Pu} \\
\mathrm{Pu} 244 \\
19.4 \\
6.54 \times 10^{5}\end{array}$ & $\begin{array}{l}\text {--Ghemical Form } \\
\text {--Isotope } \\
\text {--Density, } \mathrm{g} / \mathrm{cm}^{3} \\
\text {--Alpha Yield }\end{array}$ \\
\hline 0.01 & $4.19 \times 10^{-18}$ & $2 \times 10^{-3}$ & $3 \times 10^{-5}$ & $1 \times 10^{-7}$ & $4 \times 10^{-7}$ & $7 \times 10^{-9}$ & $5 \times 10^{-11}$ & \\
\hline 0.05 & $5.24 \times 10^{-16}$ & $2 \times 10^{-1}$ & $4 \times 10^{-3}$ & $1 \times 10^{-5}$ & $5 \times 10^{-5}$ & $8 \times 10^{-7}$ & $7 \times 10^{-9}$ & \\
\hline 0.10 & $4.19 \times 10^{-15}$ & $2 \times 10^{0}$ & $3 \times 10^{-2}$ & $1 \times 10^{-4}$ & $4 \times 10^{-4}$ & $7 \times 10^{-6}$ & $5 \times 10^{-8}$ & \\
\hline 0.50 & $5.24 \times 10^{-13}$ & $2 \times 10^{2}$ & $4 \times 10^{0}$ & $1 \times 10^{-2}$ & $5 \times 10^{-2}$ & $8 \times 10^{-4}$ & $7 \times 10^{-6}$ & \\
\hline 1.00 & $4.19 \times 10^{-12}$ & $2 \times 10^{3}$ & $3 \times 10^{1}$ & $1 \times 10^{-1}$ & $4 \times 10^{-1}$ & $7 \times 10^{-3}$ & $5 \times 10^{-5}$ & \\
\hline 5.00 & $5.24 \times 10^{-10}$ & $2 \times 10^{5}$ & $4 \times 10^{3}$ & $1 \times 10^{1}$ & $5 \times 10^{1}$ & $8 \times 10^{-1}$ & $7 \times 10^{-3}$ & \\
\hline 10.00 & $4.19 \times 10^{-9}$ & $2 \times 10^{6}$ & $3 \times 10^{4}$ & $1 \times 10^{2}$ & $4 \times 10^{2}$ & $7 \times 10^{0}$ & $5 \times 10^{-2}$ & \\
\hline
\end{tabular}

(a) Number of alpha emissions per g-second of heavy isotope. 
In the steady state all of this energy is carried away from the aerosol by conduction at the gas-particle interface. Accordingly,

$$
\dot{Q}=h\left(4 \pi r^{2}\right)\left(T-T_{\infty}\right)
$$

where $T$ is the average aerosol temperature, and $T_{\infty}$ is the temperature of the gas far from the particle. In the ideal situation the Nusselt number of a conducting sphere is identically equal to

$$
\mathrm{Nu}=\frac{\mathrm{hD}}{\mathrm{k}}=2.0 \text {, }
$$

where $k$ is the thermal conductivity of the surrounding gas, $D$ the particle's diameter, and $h$ the heat transfer coefficient at the gas-particle interface. Because of the very small peclet numbers associated with small aerosols, convective contributions to the heat transfer from such particles are normally considered negligible. As the particle sizes become smaller and approach the mean free path of the gas, a correction is required which is also neglected in this analysis. Equating Equations (2) and (3) and substituting (4) yields the following result for the temperature rise of the particle:

$$
T-T_{\infty}=\frac{E_{0} \rho Y_{\alpha} r^{2}}{3 k}
$$

Using typical property values for the highly radioactive $\mathrm{Pu}^{236}$ isotope and a representative particle size of $0.10 \mu \mathrm{m}$ yields a temperature rise of about $10^{-5}$ degrees $F$, clearly a negligible effect.

As a postulated accident proceeds, however, masses of radioactive species may be expected to congregate at selected points in the containment. A large portion will probably end up on the floor of the inner containment. As the amount of settled mass on the floor increases with time, the total amount of energy that must be dissipated by the radioactive dust layer also grows. Hence, it is possible that the floor of the containment may be heated due to the radioactive decay of the settled fuel aerosol as the accident progresses. This effect could produce thermal gradients in the containment gas resulting in upward directed thermophoretic forces on aerosol particles as well as convective gas motion causing retarded sedimentation velocities and resuspension. 
Consider, then, a uniform dust layer of thickness $\delta$ dissipating heat due to its radioactivity to a concrete floor of thickness $\Delta x$ and the gas above it having a temperature $T_{\infty}$ far from the floor. Accordingly, in the steady state, the heat conduction rate through the concrete slab may be expressed as

$$
q_{c}=k_{c} A_{F} \frac{T-T_{G}}{\Delta x}
$$

where $T$ is the temperature of the dust layer, $A_{F}$ the floor area of the containment, $k_{c}$ the thermal conductivity of the concrete, and $T_{G}$ the temperature of the ground below the concrete slab. The heat transfer rate to the containment gas above the floor is given by

$$
q_{a}=h A_{F}\left(T-T_{\infty}\right)
$$

where $h$ is the heat transfer coefficient for a heated flat surface. Using typical values of the physical properties and the following relation (presented by McAdams (1) and reported in Kreith(2)) for the Nusselt number of a heated horizontal surface

$$
\mathrm{Nu}=\frac{\mathrm{hL}}{\mathrm{k}}=0.14(\mathrm{GrPr})^{1 / 3} \text {, }
$$

where $\mathrm{Gr}$ is the Grashof number and $\operatorname{Pr}$ the Prandtl number of the gas, and $L$ is a characteristic dimension of the surface, ylelds a typical heat transfer coefficient of $3.6 \mathrm{Btu} / \mathrm{hrft}^{2} \mathrm{~F}$. The total heat dissipation rate of the dust layer must be equal to the sum of Equations (6) and (7) and for the case of al pha decay may be written as

$$
\mathrm{q}_{\mathrm{T}}=\mathrm{M}_{\mathrm{T}} \mathrm{Y}_{\alpha} \mathrm{E}_{0}
$$

Here $\mathrm{M}_{\mathrm{T}}$ is the total mass of radioactive specles on the containment floor. For beta decay, $\mathrm{Y}_{\alpha}$ and $\mathrm{E}_{\mathrm{o}}$ must reflect beta activity and beta energy rather than alpha properties. Setting $q_{T}$ equal to the sum of $q_{c}$ and $q_{a}$ and solving for the dust layer temperature yields

$$
T-T *=\frac{q_{T}}{\left(k_{c} / \Delta x+h\right) A_{F}}=\frac{M_{T} Y_{\alpha} E_{0}}{\left(k_{c} / \Delta x+h\right) A_{F}}
$$

where $T^{*}$ represents a weighted average temperature defined as 


$$
\mathrm{T} * \equiv \frac{\left(\mathrm{k}_{c} / \Delta \mathrm{x}\right) \mathrm{T}_{G}+\mathrm{hT}_{\infty}}{\mathrm{k}_{c} / \Delta \mathrm{x}+\mathrm{h}}
$$

Then using average annual amounts and activities of selected actinides released in a hypothetical core meltdown accident of a LMFBR(3) it can be shown that if 1.0 percent of the fuel gets to the reactor containment and settles to the floor then

$$
\mathrm{q}_{\mathrm{T}}=2.99 \times 10^{4} \mathrm{Btu} / \mathrm{hr} \quad \text {. }
$$

This heat generation rate is primarily due to the beta decay of the ${ }^{239} \mathrm{~Np}$ component of the core. Using typcial values of $k_{c}=0.54 \mathrm{Btu} / \mathrm{hrft} \mathrm{F}$, $\Delta x=10 \mathrm{ft}$, and $A_{F}=1.35 \times 10^{3} \mathrm{ft}^{2}$ yields

$$
\mathrm{T}-\mathrm{T}^{*}=6.0 \mathrm{~F}
$$

Further, if 10 percent of the core gets to the dust layer on the containment floor then $q_{T}$ increases by an order of magnitude and

$$
\mathrm{T}-\mathrm{T}^{*}=60 \mathrm{~F} \text {. }
$$

In neither case is the effect large enough to significantly alter the aerosol behavior in the containment. It should be noted, however, that although it is felt that Equation (13) gives the correct order of magnitude of the effect, to produce a more exact result would require an analysis for $q_{T}$ which includes the activities and decay states for all of the actinides, fission products, and structure materials that may be present in the dust layer.

\section{MOMENTUM EXCHANGE EFFECTS}

Consider next the momentum transfer between the radioactive aerosol particle and a single alpha particle upon its discharge from the aerosol. This effect may cause detachment of particles from surfaces and from other aerosol particles. The effect could also lead to enhanced agglomeration rates of radioactive aerosols by causing a random recoil 
motion of suspended particles. The maximum effect of the momentum transfer occurs if the alpha particle is emitted directly at the gas-particle interface (see References (4) and (5) for range effects in microspheres). For this case, the velocity, $v$, of the exiting alpha particle is related to the known alpha energy $E_{0}$ of the particular isotope of interest and the mass, $m$, of the alpha particle (approximately $4 \mathrm{amu}$ ) by the equation

$$
E_{0}=\frac{1}{2} \mathrm{mv}^{2}
$$

Accordingly, the momentum of the alpha particle as it leaves the surface may be written as

$$
\mathrm{p}=\sqrt{2 \mathrm{E} \mathrm{o}^{\mathrm{m}}}
$$

The conservation of momentum, then, requires that the aerosol particle experience an identical momentum increase in the opposite direction. An upper limit for the force on the aerosol particle due solely to its alpha decay may, therefore, be written as

$$
\mathrm{F} \approx \frac{4}{3} \pi \mathrm{r}^{3} \rho \mathrm{Y}_{\alpha} \sqrt{2 \mathrm{E} \mathrm{o}^{\mathrm{m}}}
$$

This hypothetical force has been calculated for various particle sizes and plutonium isotopes. The results are presented in Table 2 for later comparison.

Next consider the spherical aerosol particle sitting on a flat solid surface such as a floor. If the force computed by Equation (17) is assumed to be directed upward, it may be compared directly with other forces on the particle such as the gravitational force, adhesion or London-Van der Waals forces, etc. The gravitational force on the aerosol particle is computed from the following expression

$$
F_{\text {grav }}=\frac{4}{3} \pi r^{3} \rho g \text {. }
$$

Typical gravitational forces are presented in Table 3. Comparison of the gravitational force with the radiation forces of Table 2 for pure $\mathrm{Pu}$ aerosol as well as $\mathrm{PuO}_{2}$ reveals that the gravitational force for all practical 
TABLE 2. FORCE (DYNES) ON VARIOUS SIZED PARTICLES OF PLUTONIUM AEROSOL DUE TO ITS ALPHA DECAY

\begin{tabular}{|c|c|c|c|c|c|c|c|}
\hline $\begin{array}{c}\text { Particle } \\
\text { Radius, } \\
\mu \mathrm{m}\end{array}$ & $\begin{array}{l}\text { Particle } \\
\text { Volume, } \\
\mathrm{cm}^{3}\end{array}$ & $\begin{array}{l}\mathrm{Pu} \\
\mathrm{Pu}^{236} \\
19.4 \\
1.97 \times 10^{13} \\
5.77\end{array}$ & $\begin{array}{l}\mathrm{PuO}_{2} \\
\mathrm{Pu}_{238} \\
11.1 \\
6.47 \times 10^{11} \\
5.50\end{array}$ & $\begin{array}{l}\mathrm{PuO}_{2} \\
\mathrm{Pu}_{239} \\
11.1 \\
2.27 \times 10^{9} \\
5.15\end{array}$ & $\begin{array}{c}\mathrm{PuO}_{2} \\
\mathrm{Pu}_{240} \\
11.1 \\
8.38 \times 10^{9} \\
5.16\end{array}$ & $\begin{array}{l}\mathrm{PuO}_{2} \\
\mathrm{Pu}_{242} \\
11.1 \\
1.44 \times 10^{8} \\
4.90\end{array}$ & 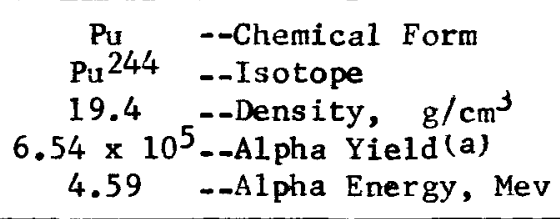 \\
\hline 0.01 & $4.19 \times 10^{-18}$ & $2 \times 10^{-17}$ & $3 \times 10^{-19}$ & $1 \times 10^{-21}$ & $4 \times 10^{-21}$ & $7 \times 10^{-23}$ & $5 \times 10^{-25}$ \\
\hline 0.05 & $5.24 \times 10^{-16}$ & $2 \times 10^{-15}$ & $4 \times 10^{-17}$ & $1 \times 10^{-19}$ & $5 \times 10^{-19}$ & $9 \times 10^{-21}$ & $7 \times 10^{-23}$ \\
\hline 0.10 & $4.19 \times 10^{-15}$ & $2 \times 10^{-14}$ & $3 \times 10^{-16}$ & $1 \times 10^{-18}$ & $4 \times 10^{-18}$ & $7 \times 10^{-20}$ & $5 \times 10^{-22}$ \\
\hline 0.50 & $5.24 \times 10^{-13}$ & $2 \times 10^{-12}$ & $4 \times 10^{-14}$ & $1 \times 10^{-16}$ & $5 \times 10^{-16}$ & $9 \times 10^{-18}$ & $7 \times 10^{-20}$ \\
\hline 1.00 & $4.19 \times 10^{-12}$ & $2 \times 10^{-11}$ & $3 \times 10^{-13}$ & $1 \times 10^{-15}$ & $4 \times 10^{-15}$ & $7 \times 10^{-17}$ & $5 \times 10^{-19}$ \\
\hline 5.00 & $5.24 \times 10^{-10}$ & $2 \times 10^{-9}$ & $4 \times 10^{-11}$ & $1 \times 10^{-13}$ & $5 \times 10^{-13}$ & $9 \times 10^{-15}$ & $7 \times 10^{-17}$ \\
\hline 10.00 & $4.19 \times 10^{-9}$ & $2 \times 10^{-8}$ & $3 \times 10^{-10}$ & $1 \times 10^{-12}$ & $4 \times 10^{-12}$ & $7 \times 10^{-14}$ & $5 \times 10^{-16}$ \\
\hline
\end{tabular}

(a) Number of alpha emissions per g-second of heavy isotope. 
TABLE 3. GRAVITATIONAL FORCE (DYNES) ON VARIOUS SIZED

PLUTONIUM AND PLUTONIUM OXIDE AEROSOL PARTICLES

\begin{tabular}{|c|c|c|c|c|}
\hline $\begin{array}{c}\text { Particle } \\
\text { Radius, } \\
\mu \mathrm{m}\end{array}$ & $\begin{array}{l}\text { Particle } \\
\text { Volume, } \\
\mathrm{cm}^{3}\end{array}$ & $\begin{array}{l}\mathrm{Pu} \\
19.4\end{array}$ & $\begin{array}{l}\mathrm{PuO}_{2} \\
11.1\end{array}$ & $\begin{array}{l}\text {--Chemical Form } \\
\text {---Density, } \mathrm{g} / \mathrm{cm}^{3}\end{array}$ \\
\hline 0.01 & $4.19 \times 10^{-18}$ & $8 \times 10^{-14}$ & $5 \times 10^{-14}$ & \\
\hline 0.05 & $5.24 \times 10^{-16}$ & $1 \times 10^{-11}$ & $6 \times 10^{-12}$ & \\
\hline 0.10 & $4.19 \times 10^{-15}$ & $8 \times 10^{-11}$ & $5 \times 10^{-11}$ & \\
\hline 0.50 & $5.24 \times 10^{-13}$ & $1 \times 10^{-8}$ & $1 \times 10^{-9}$ & \\
\hline 1.00 & $4.19 \times 10^{-12}$ & $8 \times 10^{-8}$ & $5 \times 10^{-8}$ & \\
\hline 5.00 & $5.24 \times 10^{-10}$ & $1 \times 10^{-5}$ & $6 \times 10^{-6}$ & \\
\hline 10.00 & $4.19 \times 10^{-9}$ & $8 \times 10^{-5}$ & $5 \times 10^{-5}$ & \\
\hline
\end{tabular}


particle sizes is several orders of magnitude larger than the hypothetical radiation force. This comparison alone negates any possibility of particle ejection from containment floors by this conceived physical situation. Another possible ejection scheme can be derived by assuming that the single aerosol particle is resting on a solid surface already coated with a radioactive dust layer. Diethorn ${ }^{(6)}$ has examined the rate of momentum loss from one side of a layer of radioactive material with a recoil plate on the other side. If it is assumed that an aerosol particle sits directly on the dust layer and absorbs all of the radiant energy emitted by the layer from an area equal to the aerosol's cross-sectional area, it is then possible to estimate the force due to radiation from the dust layer. For the case of a layer of $\mathrm{Pu}^{238}$ having a thickness equal to the alpha range in $\mathrm{Pu}^{238}$, a $1.0 \mu \mathrm{m}$ absorbing aerosol particle experiences a force of approximately $3 \times 10^{-12}$ dyne. Similarly, a $0.1 \mu \mathrm{m}$ aerosol finds a $3 \times 10^{-14}$ dyne force exerted on it. Again, the gravitational force predominates by several orders of magnitude the dust layer radiation force.

Furthermore, typical adhesion forces between particles and between particles and surfaces are reportedly in the range of 0.01 to 12.56 dynes for material combinations presented by Corn (7). Clearly, the London-Van der Waals forces are strongly dependent upon material combinations, but plutonium species would have to exhibit behavior orders of magnitude different from materials already studied in order that radiation forces could play a significant role. These order of magnitude estimates clearly indicate that particle ejection from either vertical or horizontal surfaces (either dusty or clean) due solely to alpha emission recoil is most improbable.

Momentum exchange between an aerosol and an alpha particle may also effect the agglomeration rate of the airborne species. Thus, one might expect aerosol particles composed of a high $\alpha$-particle yleld material such as $\mathrm{Pu}^{236}$ to experience a modification of their Brownian motion due to recoll reaction to $\alpha$-particle emission and such a modification would necessarily affect the agglomeration rate between these particles. 
Considering particles composed purely of $\mathrm{Pu}^{236}$, it can be shown that a particle of radius $0.005 \mathrm{\mu m}$ has a recoil stopping distance that is an order of magnitude larger than the particle's radius ${ }^{(8)}$. It is very much greater than the stopping distance due to a single gas molecule collision and is indeed comparable to the "mean free path" of the particle, defined as the distance traveled before changing course by ninety degrees ${ }^{(8)}$. A $0.005 \mathrm{Hm}$ particle, however, experiences only about one $\alpha$ emission per hour, whereas during this time the number of gas molecule collisions responsible for Brownian motion is astronomical. In order to correctly assess the effect due to recoil, therefore, it is necessary to account for the number of recoils per unit time.

Since the particles' recoil velocities have arbitrary directions, a net displacement will occur as a result of statistical fluctuations such as those of the random walk problem. Indeed, the analysis of that problem is applicable here if two requirements are met:

(1) the number of $\alpha$-decays during the time considered is large, and

(2) the recoil motion comes to rest between emissions. The time period during which the recoil problem can be considered is restricted to the period between aerosol particle collisions due to Brownian motion. Taking the half-life of a system undergoing Brownian coagulation as a measure for the latter, one finds that for systems with extreme particle density $\left(10^{9}\right.$ particles $\left./ \mathrm{cm}^{3}\right)$ one is restricted to periods of a few seconds or less. This is sufficiently long for a $1 \mathrm{\mu m}$ radius particle of $\mathrm{Pu}^{236}$ to emit $5 \times 10^{3} \alpha$-particles, thus, fulfilling the first requirement.

The relaxation time, $T$, of a particle is given by

$$
\tau=\frac{\mathrm{m}}{6 \pi n \mathbf{r}} \mathrm{C}(\mathbf{r})
$$

where

$$
\begin{aligned}
C(r)= & \text { the Cunningham fluid drag correction for large Knudsen } \\
& \text { number } \\
m= & \text { particle mass } \\
\eta= & \text { viscosity of the gas } \\
r & =\text { particle radius. }
\end{aligned}
$$


Using $\tau$ as a measure of the time required for particle recoil motion to come to rest, we have for a $1.0 \mu \mathrm{m}$ particle

$$
\tau=2.4 \times 10^{-4} \mathrm{sec} \text {. }
$$

The time between $\alpha$-particle emissions for such a particle is, on the other hand, $6.3 \times 10^{-4} \mathrm{sec}$, so that the second requirement is also approximately met. Using the definitions

$$
\begin{aligned}
\mathrm{Y}_{\alpha}= & \text { the } \alpha \text {-particle yield of the material composing the } \\
& \text { aerosol particle, and } \\
\ell= & \text { the length of the aerosol particle recoil path due to } \\
& \text { a single } \alpha \text {-particle emission, }
\end{aligned}
$$

and assuming that the random-walk analysis holds, the probability for a net displacement of $x$ in $d x$ along the $x$-axis in a time period, $t$, is (9)

$$
\text { with } \quad \begin{aligned}
\mathrm{P}_{\alpha}(\mathrm{x}) \mathrm{dx} & =\frac{1}{\sqrt{2 \pi} \lambda} e^{-\mathrm{x}^{2} / 2 \lambda^{2}} \mathrm{dx} \\
\lambda^{2} & =\frac{1}{3} e^{2} \mathrm{y}_{\alpha} \mathrm{mt} .
\end{aligned}
$$

The solution to the diffusion equation with appropriate boundary conditions ylelds similarly, for the probability of the same effect due to Brownian motion,

$$
P_{B}(x) d x=\frac{1}{\sqrt{4 \pi} \sqrt{D_{B} t}} e^{-x^{2} / 4 D_{B} t} d x
$$

where

$$
D_{B}=\text { the diffusivity of Brownian motion. }
$$

We can, therefore, by analogy identify a diffusivity, $D_{\alpha}$, of $\alpha$-particle recoil:

$$
\mathrm{D}_{\alpha}=\frac{1}{6} \ell^{2} \mathrm{Y}_{\alpha}^{\mathrm{m}}
$$

This diffusivity can be incorporated in the expression for the agglomeration frequency as follows. Noting that the mean square displacement due to Brownian diffusion alone is 


$$
\overline{x_{B}^{2}}=2 D_{B} t
$$

and that due to $\alpha$-particle recoil alone is

$$
\overline{x_{\alpha}^{2}}=2 D_{\alpha} t
$$

we see that

$$
\overline{\left(x_{\alpha}+x_{B}\right)^{2}}=\overline{x_{\alpha}^{2}}+\overline{x_{B}^{2}}+2 \bar{x}_{\alpha} \bar{x}_{B}=2\left(D_{\alpha}+D_{B}\right) t
$$

since the two effects are statistically independent. The diffusivities, therefore, add and the expression for the agglomeration frequency due to both mechanisms becomes:

$$
R\left(r, r^{\prime}\right) d r d r^{\prime}=4 \pi\left(D_{\alpha}+D_{B}+D_{\alpha}^{\prime}+D_{B}^{\prime}\right)\left(r+r^{\prime}\right) n(r) n\left(r^{\prime}\right) d r d r^{\prime},
$$

where

$$
\begin{aligned}
R\left(r, r^{\prime}\right) d r d r^{\prime}= & \text { frequency of collision between particles of radius } \\
& r \text { in } d r \text { and those of radius } r^{\prime} \text { in } d r^{\prime} \\
n(r)= & \text { number density of particles of radius } r \\
n\left(r^{\prime}\right)= & \text { number density of particles of radius } r^{\prime} .
\end{aligned}
$$

The effect of $\alpha$-particle recoil on Brownian coagulation can, therefore, be assessed by comparing values of $\mathrm{D}_{\mathrm{B}}$ and $\mathrm{D}_{\alpha}$. To do so we need to develop an expression for $l$, the $\alpha$-particle recoil path length.

Given a relaxation time, $\tau$, and initial velocity due to recoil, $v_{0}$, the recoil path length, $\ell$, is just

$$
l=\mathrm{v}_{\mathrm{o}}{ }^{\top}
$$

By Equation (15), however,

$$
v_{0}=\frac{p}{m}=\frac{1}{m} \sqrt{2 m_{\alpha} E_{0}},
$$

where

$$
\begin{aligned}
& \mathrm{m}_{\alpha}=\alpha \text {-particle mass } \\
& \mathrm{E}_{\mathrm{o}}=\alpha \text {-particle kinetic energy, }
\end{aligned}
$$


so that, with Equation (20) for $T$ and $\rho=$ aerosol particle material density:

$$
D_{\alpha}=\frac{Y_{\alpha} m_{\alpha} E_{0} \rho r}{81 \pi n^{2}} c^{2}(r)
$$

The diffusivity due to Brownian motion is just

$$
D_{B}=\frac{k T}{6 \pi \eta r} C(r)
$$

$$
\text { with } \quad \begin{aligned}
\mathbf{k} & =\text { Boltzmann constant } \\
\mathrm{T} & =\text { absolute temperature. }
\end{aligned}
$$

Their ratio is, therefore

$$
\frac{\mathrm{D}_{\mathrm{B}}}{\mathrm{D}_{\alpha}}=\frac{27 n \mathrm{kT}}{2 \mathrm{Y}_{\alpha} \mathrm{m}_{\alpha} \mathrm{E}_{0} \rho \mathrm{r}^{2} \mathrm{C}(\mathrm{r})}
$$

We can calculate this ratio for the extreme example of a pure $\mathrm{Pu}^{236}$ particle. In this case,

$$
\begin{aligned}
& E_{o}=5.77 \quad M e v \\
& Y_{\alpha}=1.97 \times 10^{13} \mathrm{gm}^{-1} \mathrm{sec}^{-1}
\end{aligned}
$$

and with

$$
\begin{aligned}
\mathrm{m}_{\alpha} & =6.6 \times 10^{-24} \mathrm{gm} \\
\eta & =1.83 \times 10^{-4} \text { poise } \\
\rho & =19.4 \mathrm{gm} / \mathrm{cm}^{3}, \\
& \frac{D_{B}}{D_{\alpha}}=4.4 \times 10^{-3} \frac{1}{r^{2} \mathrm{C}(\mathrm{r})} .
\end{aligned}
$$

Then for a $1.0 \mu \mathrm{m}$ particle

$$
\frac{\mathrm{D}_{\mathrm{B}}}{\mathrm{D}_{\alpha}}=4.4 \times 10^{5}
$$

Clearly, then, $\alpha$-particle emission has a negligible effect on particle agglomeration. 


\section{ELECTRICAL CHARGING EFFECTS}

Charging of radioactive aerosol particles occurs immediately upon the emission of an alpha or beta particle since these "swift particles" by definition carry charges away from the aerosol (neglecting range effects within the aerosol) leaving behind extra electrons or protons. The chain of events which may occur following this charging process depends upon the electrical properties of the aerosol material as well as the reaction of the surrounding medium to the emission of these "swift particles". For the case of an alpha-emitting aerosol suspended in a gaseous medium, the emitted alpha particle as it travels through the adjacent gas dissipates its energy chiefly by interaction with the gas molecules causing ionization of the surrounding vapor. In fact, experiments have shown that an average of 35 electron volts of energy are dissipated for each ion pair formed in air ${ }^{(10)}$. These gaseous lons then, upon collisions with the aerosol particle, may tend to discharge it if the aerosol material is conductive and can transfer charge easily. On the other hand, if the aerosol material is nonconductive in nature, a charged layer of adsorbed Ions may develop on the surface of the aerosol while the immobile excess charge due to the alpha emission remains buried.

For the case of a conductive aerosol particle in a gaseous medium, the charging and discharging rates were previously calculated and compared ${ }^{(8)}$. It was conclusively determined that electrical charging could not exert a significant effect on the aerosol behavior for this case. Similarly, a dust layer composed of conductive aerosol particles can be expected to transfer any localized charge build-up and remain effectively neutral. Hence, the charging effects for nonconductive aerosols are considered here.

Consider first a single nonconductive aerosol particle buried in either a nonconductive dust layer or an agglomerate. The various radioactive isotopes that may be present in a postulated accident situation may be scattered throughout the containment and, hence, found throughout the dust layer. The various species, of course, decay with differing 
rates and it is therefore conceivable that "hot spots" may exist in the layer. "Hot spots" may also develop due simply to statistical fluctuations in the dacay rate within a dust layer composed of a single species. In any case, it is quite possible that areas of significant charge build up may occur in the nonconductive dust layer. To get an order of magnitude estimate of the electrical forces on these buried aerosol particles, consider two touching identically sized spherical particles accruing equal charge due solely to their radioactive decay. The repulsive coulombic forces on the particles are calculated by assuming that charges are concentrated at the particles' centers. Consequently, the coulombic force may be approximated as

$$
F=\frac{Q^{2}}{16 \pi \epsilon_{0}}\left(\frac{1}{r^{2}}\right),
$$

where $\epsilon_{0}$ is the permittivity of free space, $r$ the particles' radii, and $Q$ the charge on each sphere. $Q$ increases with time as the radioactive species decay and may be written

$$
Q=\frac{8}{3} \pi r^{3} \rho \quad Y_{\alpha}(\Delta t) e
$$

where $\Delta t$ is the length of time for which charges have been accuring and $e$ the charge of an electron. Substitution of Equation (38) into (37) yields an approximation for the time dependent coulombic forces on the particles:

$$
F=\frac{4 \pi r^{4} \rho^{2} Y_{\alpha}{ }^{2}(\Delta t)^{2}}{9 \epsilon_{0}} .
$$

The forces of adhesion binding the particles together are expected to be on the order of 1.0 dyne (see Reference (7)). Equating (39) to 1.0 dyne and solving for $\Delta t$ yields an estimate for the time required to build up enough charge to overcome the adhesion forces. Accordingly,

$$
\Delta t=\sqrt{\frac{9 \varepsilon_{0}}{4 \pi r^{4} \rho^{2} Y_{\alpha}^{2}}}
$$

Table 4 gives approximate times required for the electrical forces to approach typical adhesion force magnitudes for particles of various sizes 
TABLE 4. APPROXIMATE TTMES (SEC) REQUIRED FOR ELECTRICAL FORCES ON TWO EQUAL,

TOUCHING SPHERES TO APPROACH TYPICAL LONDON VAN DER WAALS ADHESION FORCES

\begin{tabular}{|c|c|c|c|c|c|c|c|}
\hline $\begin{array}{c}\text { Particle } \\
\text { Radius, } \\
\mu^{m}\end{array}$ & $\begin{array}{c}\mathrm{Pu}_{236} \\
\mathrm{Pu}^{236} \\
19.4 \\
1.97 \times 10^{13} \\
\end{array}$ & $\begin{array}{c}\mathrm{PuO}_{2} \\
\mathrm{Pu}_{238} \\
11.1 \\
6.47 \times 10^{11} \\
\end{array}$ & $\begin{array}{c}\mathrm{PuO}_{2} \\
\mathrm{Pu}_{239} \\
11.1 \\
2.27 \times 10^{9} \\
\end{array}$ & $\begin{array}{c}\mathrm{PuO}_{2} \\
\mathrm{Pu}^{240} \\
11.1 \\
8.38 \times 10^{9} \\
\end{array}$ & $\begin{array}{c}\mathrm{PuO}_{2} \\
\mathrm{Pu}_{242} \\
11.1 \\
1.44 \times 10^{8} \\
\end{array}$ & $\begin{array}{c}\mathrm{Pu} \\
\mathrm{Pu}^{244} \\
19.4 \\
6.54 \times 10^{5} \\
\end{array}$ & $\begin{array}{l}\text {--Chemical Form } \\
\text {--Isotope } \\
\text {--Density, } \mathrm{g} / \mathrm{cm}^{3} \\
\text {--Alpha Yield }(\mathrm{a})\end{array}$ \\
\hline 0.01 & $1.30 \times 10^{6}$ & $6.93 \times 10^{7}$ & $1.98 \times 10^{10}$ & $5.35 \times 10^{9}$ & $3.11 \times 10^{11}$ & $3.92 \times 10^{13}$ & \\
\hline 0.05 & $5.21 \times 10^{4}$ & $2.77 \times 10^{6}$ & $7.90 \times 10^{8}$ & $2.14 \times 10^{8}$ & $1.25 \times 10^{10}$ & $1.57 \times 10^{12}$ & \\
\hline 0.10 & $1.30 \times 10^{4}$ & $6.93 \times 10^{5}$ & $1.98 \times 10^{8}$ & $5.35 \times 10^{7}$ & $3.11 \times 10^{9}$ & $3.92 \times 10^{11}$ & \\
\hline 0.50 & $5.21 \times 10^{2}$ & $2.77 \times 10^{4}$ & $7.90 \times 10^{6}$ & $2.14 \times 10^{6}$ & $1.25 \times 10^{8}$ & $1.57 \times 10^{10}$ & \\
\hline 1.00 & $1.30 \times 10^{2}$ & $6.93 \times 10^{3}$ & $1.98 \times 10^{6}$ & $5.35 \times 10^{5}$ & $3.11 \times 10^{7}$ & $3.92 \times 10^{9}$ & \\
\hline 5.00 & $5.21 \times 10^{0}$ & $2.77 \times 10^{2}$ & $7.90 \times 10^{4}$ & $2.14 \times 10^{4}$ & $1.25 \times 10^{6}$ & $1.57 \times 10^{8}$ & \\
\hline 10.00 & $1.30 \times 10^{0}$ & $6.93 \times 10^{1}$ & $1.98 \times 10^{4}$ & $5.35 \times 10^{3}$ & $3.11 \times 10^{5}$ & $3.92 \times 10^{7}$ & \\
\hline
\end{tabular}

(a) Number of alpha emissions per g-second of heavy isotope. 
and of several plutonium isotopes. The larger particles having more mass and consequently experiencing higher alpha emission rates, accrue charges faster than the smaller ones and hence require less time to achieve the necessary force for detachment.

It should be noted that the London-Van der Waals attractive force between two molecules is strongly dependent upon the separation distance $\delta(7,11)$ between them

$$
\mathrm{F}=\lambda \delta^{-7},
$$

where $\lambda$ is the Van der Waals constant for attraction. Equation (37) indicates that the electrical forces depend on $r^{-2}$. Consequently, once the electrical force attains sufficient magnitude to overcome the adhesion forces and the particles separate slightly, the electrical force quickly dominates and the particles recoil apart. Table 4 indicates that this may be a physically possible ejection mechanism when large, highly active species are present. However, only through small scale experiments could the presence or absence of such a scheme be certainly determined.

Charging effects on agglomeration rates will now be considered. To analyze the effect of charging on particle agglomeration rates, data and mathematical models from meteorological investigations have been frequently invoked. The systems encountered there differ quantitatively from the nuclear accident system so that direct application of some of the relations and data is problematical. Nevertheless, since no directly applicable theories appear to be available and the results produced with the existing theories (which may be expected to give order-ofmagnitude results) clearly show negligible effects for most cases, these procedures seem justified.

To look at the extreme case, choose a spherical aerosol particle of radius $\mathrm{a}=1.0 \mu \mathrm{m}$ composed of $\mathrm{Pu}^{236}$. Such a particle will experience $1.6 \times 10^{3} \alpha$-disintegrations per second and all of the $\alpha$-particles so created will escape the particle. For, using the Bragg-Kleeman rule(12)

$$
R_{2} / R_{1}=\rho_{1} \sqrt{A_{2}} / \rho_{2} \sqrt{A_{1}}
$$


where

$$
\begin{aligned}
& R_{1}=\alpha \text {-particle range in substance } 1 \\
& \rho_{i}=\text { density of substance } 1 \\
& A_{i}=\text { atomic mass of substance } 1
\end{aligned}
$$

and the measured value of $R$, for $5.5 \mathrm{Mev} \alpha$-particles in $\mathrm{PuO}_{2}$ (13),

$$
R_{1}=11.7 \mu \mathrm{m}
$$

the range of the $\alpha$-particles emitted by $\mathrm{Pu}^{236}$ in $\mathrm{Pu}^{236}$ is

$$
\mathrm{R}=6.7 \mu \mathrm{m} \quad \text {. }
$$

Since this is significantly greater than $2 r=2 \mu \mathrm{m}$, all of the emitted $\alpha$-particles escape the aerosol particle while retaining most of their initial energy.

This energy is disslpated by ionization of the surrounding gas. The number of ion pairs so produced can be taken as equal to the average for $\alpha$-disintegrations in the atmosphere ${ }^{(14):} 2 \times 10^{5}$ ion pairs per $\alpha$-disintegration. The total number of ion pairs produced by the 1- $\mu m$ particle per second is therefore

$$
1.6 \times 10^{3} \times 2 \times 10^{5}=3.2 \times 10^{8} \text { ion } \mathrm{pairs} / \mathrm{sec} .
$$

The range of $5.8 \mathrm{Mev} \alpha$-particles in air is about $4 \mathrm{~cm}(12)$. Since this number is much greater than the particle separation distance $\left(\cong 1 / N^{1 / 3}\right.$, where $N$ is the particle number density) expected, the fon pair density created by a single $1.0 \mu \mathrm{m}$ aerosol particle per second is

$$
q_{\text {source }}=3.2 \times 10^{8} \mathrm{~N} \mathrm{~cm}^{-3} \mathrm{sec}^{-1} \text {. }
$$

In the above, it is tacitly assumed that the $\alpha$-particle is doubly charged as it leaves the aerosol particle (a neutral $\alpha$-particle, or helium atom, does not ionize the surrounding gas). This is not necessarily so. What charge the $\alpha$-particle carries with it depends on the interaction of $\alpha$ and aerosol particle. There are three possibilities: 
(1) The $\alpha$-particle recombines with one or two electrons before leaving the particle. This is not very likely since recombination is favored by low $\alpha$-particle velocities which do not occur in sma11 aerosol particles. Even at low velocities, a continual exchange of electrons between $\alpha$ and aerosol particle can be expected so that the $\alpha$-particle will be emitted with some average charge.

(2) The energy released by the o-particle during its interaction with the aerosol particle projects a sufficient number of electrons into the conduction band to create a conduction path along the track of the $\alpha$-particle. Any charge left in the interior of the aerosol particle will then immediately move to the surface.

(3) The charge created by emission of an $\alpha$-particle remains in the interior of the aerosol particle subject to a slow migration rate to the surface. In this case the aerosol particle polarizes and assumes an effective negative surface charge distribution. Assuming symmetry, the electric field exterior to the particle is then just that due to its total charge, taken to be at its center. Experiments with $\beta$-irradiation of Plexiglas and carbona wax sheets (15) support the third possibility. They show a charge polarization that persists in normal atmosphere $\left(\sim 300\right.$ ion pairs $\left./ \mathrm{cm}^{3}\right)$ with a half -1 ife of $\sim 9$ days. Therefore, in the following it has been assumed that $\alpha$-particles are emitted from the aerosol particle with their charge intact. The aerosol particle itself is assumed polarized with an effective, uniformly distributed surface charge. It should be noted, however, that the conclusions of this analysis are not qualitatively altered by invoking one of the other possible charge states and, in fact, apply equally well to conducting particles.

The surface charge state of the aerosol particle, created by emission of charged $\alpha$-particles, is continually modified by the diffusion and adhesion of ions of either charge to the particle. In the following it will be shown that an equilibrium state evolves, the average charge 
of an aerosol particle will be calculated, and finally, the effect of this charge on the agglomeration rate of the aerosol particles will be calculated.

The monatomic or diatomic ions and electrons created by passage of $\alpha$-particle through the air cluster with neutral atoms within fractions of a second (16) to form characteristic small ions of either sign. The electric mobility, $Z$, of the negative ions is found to be slightly larger than that of the positive lons. For an order of magnitude calculation, it will be sufficient to use the average for both in the atmosphere(14)

$$
\mathrm{z} \approx 1.4 \mathrm{~cm}^{2} / \mathrm{v}-\mathrm{sec}
$$

Their diffusivities, $D$, are on the average (14)

$$
\mathrm{D} \approx 3 \times 10^{-2} \mathrm{~cm}^{2} / \mathrm{sec} .
$$

As suming $\mu$ elemental charges, e, on a $1.0 \mu \mathrm{m}$ particle, the exterior electric field, $E$, is

$$
E=\frac{\mu e}{4 \pi \epsilon{ }_{0} r^{2}}
$$

where $r$ is the radial distance from the center of the particle. At its surface

$$
E=1.4 \times 10^{1} \mu \mathrm{m} \text { volts } / \mathrm{cm}
$$

and the flux $\phi_{\mathrm{E}}$ of ions to the particle due to an ion concentration $n$ far from the particle is

$$
\phi_{\mathrm{E}}=\mathrm{ZEn}=2.0 \times 10^{1} \mu \mathrm{m} \mathrm{cm}^{-2} \mathrm{sec}^{-1}
$$

The flux, $\phi_{\mathrm{D}}$, of ions due to diffusion is, on the other hand,

$$
\phi_{D}=D \frac{\partial n}{\partial r} \approx D_{a}^{n}=3 \times 10^{2} \mathrm{ncm}^{-2} \sec ^{-1} \text {. }
$$

Thus the flux of ions to the particle due to charge on the particle becomes significant when this charge exceeds 15 elemental units. This is in agreement with Millikan's observation that for particles with as many as 17 negative elemental charges, there is a preponderance of negative ion flux to the particle ${ }^{(17)}$. 
The fact that a charged particle will accumulate about itself a net ionic (or space) charge of opposite sign has, however, been neglected so far. This can be accounted for, at equilibrium, by a shielding factor to the electric potential 6 of the particle:

$$
\phi \rightarrow \phi e^{-u r}
$$

where

$$
\begin{array}{r}
\qquad x^{2}=\frac{4 \pi e^{2}}{k T} n \\
k=\text { Boltzmann's constant } \\
T=\text { absolute temperature, }
\end{array}
$$

and $x^{-1}$ is the Debye-Huckel length (19). Anticipating an equilibrium ion concentration of $\mathrm{n} \approx 6 \times 10^{10} \mathrm{~cm}^{-3}$ for $10^{6} 1.0 \mu \mathrm{m}$ aerosol particles/ $\mathrm{cm}^{3}$ at room temperature,

$$
x^{-1} \approx 5 \mu \mathrm{m}
$$

Indicating a strong shielding effect. This shielding effect acts to enhance the relative dominance of thermal diffusion of ions to the particle and we may, therefore, in the following calculation of the ion equilibrium concentration neglect particle-ion electrical interaction.

The time rate of change of the ion concentration $n$ can, therefore, be written

$$
\frac{d n}{d t}=-\alpha n^{2}+q_{\text {source }}-q_{\text {sink }}
$$

where

$$
\begin{aligned}
\alpha= & \text { ion recombination coefficient } \\
& \approx 1.6 \times 10^{-6} \mathrm{~cm}^{3} / \mathrm{sec} \text { in air }(14) \\
= & \text { number of ions created per } \mathrm{cm}^{3} \text { per sec } \\
q_{\text {source }}= & \text { number of ions adsorbed to aerosol particles per } \\
\mathrm{q}_{\text {sink }} & \mathrm{cm}^{3} \text { per sec. }
\end{aligned}
$$

Writing, in the first approximation, $q_{\text {sink }}=4 \pi a \mathrm{DnN}$,

where

$$
\begin{aligned}
& a=\text { radius of aerosol particle } \\
& N=\text { number of aerosol particles per } \mathrm{cm}^{3},
\end{aligned}
$$

the equation becomes 


$$
\frac{d n}{d t}=-\alpha n^{2}-4 \pi a D N n+q_{\text {source }},
$$

which has the solution

$$
\left|\frac{2 \alpha n+b-\gamma}{2 \alpha n+b+\gamma}\right|=\left|\frac{2 \alpha n_{0}+b-\gamma}{2 \alpha n_{0}+b+\gamma}\right| e^{-\gamma\left(t-t_{0}\right)}
$$

with

$$
\begin{aligned}
& \mathrm{n}=\mathrm{n}_{\mathrm{o}} \text { at } \mathrm{t}=\mathrm{t}_{\mathrm{o}} \\
& \mathrm{b}=4 \| \text { aDN } \\
& y=\left(\mathrm{b}^{2}+4 \alpha \mathrm{q}_{\text {source }}\right)^{1 / 2} .
\end{aligned}
$$

The steady-state concentration is, therefore,

$$
\mathrm{n}_{\text {equ }}=\frac{-\mathrm{b}+\gamma}{2 \alpha}
$$

and is reached exponentially with time constant

$$
\tau=Y^{-1} \text {. }
$$

Using $a=10^{-4} \mathrm{~cm}$ and a typical aerosol concentration, $\mathrm{N}=10^{6} \mathrm{~cm}^{-3}$, these become

$$
\begin{aligned}
\mathrm{n}_{\text {equ }} & \approx 6 \times 10^{6} \mathrm{~cm}^{-3} \\
\tau & \approx 10^{-5} \mathrm{sec} .
\end{aligned}
$$

(It is interesting to note that our formula for $\tau$ reproduces the values 100-300 sec found for atmospheric conditions.)

It may be assumed from the above that the system quickly attains equilibriull. Under this condition, neglecting the slightly higher diffusivities and electrical mobilities of the negative fons, the distribution of charges on the aerosol particles, independent of their initial charge is (16)

$$
f(\mu)=\frac{1}{\Sigma} e^{-(\mu e)^{2} / 2 a k T}
$$

with

$$
\Sigma=\sum_{-\infty}^{\infty} \mathrm{e}^{-(\mu \mathrm{e})^{2} / 2 \mathrm{akT}}
$$


This expression is the standard Boltzmann distribution for charges as dependent on particle size and has been validated in practice. This distribution of charges has been found to result when artificially ionized atmospheres are used to "discharge" initially highly charged aerosols(16).

The average charge on an aerosol particle is, therefore,

$$
\bar{\mu}=\sum_{\mu=0}^{\infty} \mu f(\mu) \approx \int_{0}^{\infty} \mathrm{d} \mu \mu f(\mu)=\sqrt{\frac{a k T}{\pi e^{2}}} .
$$

At $300 \mathrm{~K}$ a $1.0 \mu \mathrm{m}$ particle has on the average, therefore, between two and three elementary charges of either sign.

If one neglects the Debye-Hückel shielding effect which tends to reduce electrical effects on agglomeration, the collision rate for particles of radius $a$, and charge $\mu_{1}$, with those of radius $a_{2}$ and charge $\mu_{2}$ is $(19)$

$$
R=R_{0}{ }^{Z} \mu_{1} \mu_{2}
$$

where

$$
z_{\mu_{1} \mu_{2}}=\frac{\mu_{1} \mu_{2} e^{2} / k T\left(a_{1}+a_{2}\right)}{\exp \left(\mu_{1} \mu_{2} e^{2} / k T\left(a_{1}+a_{2}\right)\right)-1}
$$

and $R_{0}$ is the collision rate due to Brownian motion. Using the equilibrium average $\left|\mu_{1}\right|=\left|\mu_{2}\right|=3$ and $a_{1}=a_{2}=1 \mu \mathrm{m}$,

$$
\begin{aligned}
& Z_{+3,3}=0.88 \\
& Z_{-3,3}=1.13
\end{aligned}
$$

at room temperature. Since these values spread symmetrically about 1.0 , an equal distribution of positively and negatively charged particles results in little net change in the agglomeration rate as a result of particle charge. 


\section{CONCLUSIONS}

In summary, aside from one possible mechanism, each of the physical schemes presented in this report as exerting possible influences on the behavior of aerosol particles in postulated accident situations have been found to be negligible. It is felt that localized "hot spots" within nonconductive dust layers or agglomerates may, in fact, lead to particle ejections. The scheme requires verification that, indeed, localized "hot spots" do exist in the dust layer and that the particles in the "hot spots" retain their charge for a sufficient length of time for the coulombic forces to overcome the London-Van der Waals adhesion forces. In short, there must be a few highly active particles surrounded by less active ones and the layer must be electrically nonconductive. The absence or presence of such a mechanism may only be determined by small scale experiments with dust layers composed of representative amounts of LMFBR actinides, fission products, structural, and coolant materials. 


\section{REFERENCES}

(1) McAdams, W. H., "Heat Transmission", Third Edition, McGraw-Hi11, New York (1954).

(2) Kreith, F., "Principles of Heat Transfer", Second Edition, International Textbook Company, Scranton, Pennsylvania (1965).

(3) Erdman, C. A. and Reynolds, A. B., Nuclear Safety, 16, 43 (1975).

(4) Kershner, C. J., "Se1f-Absorption and Energy Spectrum Distortion of Alpha Particle Emission from Microspherical Sources", MLM-1655, August 22, 1969.

(5) Huffman, G. N., "The Effective Alpha Activity of Plutonium-238 Dioxide Microspheres", MLM-1642, April 1969.

(6) Diethorn, W., "Alpha Sources for Low-Thrust Tasks in Space", Intern. J. App1. Radiation Isotopes, 15, 127-31 (1964).

(7) Corn, M., "Adhesion of Particles", In Aerosol Science, edited by C. N. Davies, Academic Press, New York (1966).

(8) Gieseke, J. A., and Reed, I. D., "Aerosol Behavior Modeling for Fast Reactor Safety: FY1975 Annual Report", BMI-X-662, October, 1975.

(9) Kennard, E. H., "Kinetic Theory of Gases", McGraw-Hil1, New York (1938).

(10) Friedlander, G., Kennedy, J. W., and Miller, J. M., "Nuclear and Radiochemistry", John Wiley, New York (1964).

(11) Lennard-Jones, J. E., Proc. Phys. Soc. (London) 43, 461 (1931).

(12) Evans, R. D., "The Atomic Nucleus", McGraw-Hi11, New York (1955).

(13) Huffman, G. N., and Kershner, C. J., Nuclear Applications and Technology, 9, 434 (1970).

(14) Bricard, J., and Pradel, J., in Aerosol Science, edited by C. N. Davies, Academic Press, London (1966).

(15) Fish, B. R., and Walker, R. L., ORNL-P-1313, CONF-650407-4 (1965).

(16) Whitby, K. T., and Liu, B. Y., in Aerosol Science, edited by C. N. Davies, Academic Press, London (1966) 


\section{REFERENCES}

(Continued)

(17) Millikan, R. A., Phys. Rev, , 32, 349 (1911); quoted by Gunn, R. J. of Meteor. 11, 339 (1954).

(18) Landau, L. D., and Lifschitz, E. M., "Statistical Physics", Addison-Wesley, Reading, Massachusetts (1958).

(19) Zebel, G., in Aerosol Science, edited by C. N. Davies, Academic Press, London (1966). 